Universidad y Economía Social: la producción local de sentidos

Romina Salvade, Santiago Diomedi Ollier

http://perio.unlp.edu.ar/ojs/index.php/question/article/view/4706

Cita sugerida: Salvade, R., y Diomedi Ollier, S. (2018). Universidad y economía social: la producción local de sentidos.

Question, 1(59), e085. doi:https://doi.org/10.24215/16696581e085

\title{
Universidad y economía social: la producción local de sentidos
}

University and social economy: local production of meanings

Romina Salvade rominasalvade@gmail.com

http://orcid.org/0000-0001-9048-7016

Facultad de Ciencias Sociales; Universidad Nacional del

Centro de la provincia de Buenos Aires (Argentina)

Santiago Diomedi Ollier olliersantiago@gmail.com

http://orcid.org/0000-0002-2345-4924

Facultad de Ciencias Sociales; Universidad Nacional del

Centro de la provincia de Buenos Aires (Argentina)

\section{Resumen}

Este trabajo busca compartir algunas reflexiones -de carácter incipiente- respecto a la producción local de sentidos en torno a la Economía Social y Solidaria desde las diferentes perspectivas de los actores que se enmarcan en ella. Concretamente, nos interesa abordar los significados que emergen de las visiones y representaciones puestas a definir y delimitar aquello que compete a la Economía Social y Solidaria (ESS) y, por ende, caracteriza e identifica a los productores. Desde allí entendemos a la ESS como campo de entrecruces que entrama y en el que se enmarcan actores y prácticas en tensión, cuyas configuraciones de sentidos deben ser analizados a luz de las posiciones/relaciones emergentes de procesos de construcción (inter)subjetiva. En este sentido advertimos lo que no puede ser sino un doble 
desafío para el quehacer universitario, en la medida en que nos interpela a pensar a la universidad como productora de ESS, sin soslayar la especificidad de su trabajo y posibilidades de aporte.

Palabras clave: universidad; economía social; sentidos; prácticas.

\section{Abstract}

This work seeks to share some reflections -of incipient character- regarding the local production of meanings around the Social and Solidarity Economy from the different perspectives of the actors that are part of it. Specifically, we are interested in addressing the meanings that emerge from the visions and representations set out to define and delimit what belongs to the Social and Solidarity Economy (ESS) and, therefore, characterizes and identifies the producers. From there we understand the ESS as a field of intersecting networks and in which actors and practices in tension are framed, whose configurations of meanings must be analyzed in light of the positions / relationships emerging from (inter) subjective construction processes. In this sense we see what can only be a double challenge for university work, insofar as it challenges us to think of the university as a producer of ESS, without ignoring the specificity of its work and possibilities of contribution.

Keywords: university; social economy; senses; practices.

\section{La indisciplina del concepto}

No parece encontrarse una definición uniforme, estable o consensuada respecto a lo que hace a la Economía Social (ES), solidaria (ESS) y/o popular (ESSyP). Es difícilmente discutible, sin embargo, la relación que hace a la "economía" y a lo "social". De hecho, la ES se ubica dentro de una corriente teórica y política que resulta "inseparable de la crítica a la doctrina económica 'formal', defensora a ultranza de la utopía de un sistema de mercados autorregulado mecánicamente, libre de interferencias sociales o estatales" (Coraggio, 2016: 17). En tal sentido, no es una obviedad comenzar por preguntarse qué es la Economía Social. Reflexiones de tal índole suelen encabezar los trabajos que la enfocan, sea desde el aporte a la reconstrucción histórica de la categoría o bien desde el análisis localizado sobre las experiencias de los actores. Este trabajo no será una excepción. 
Pese a que su caracterización sea esquiva a alcanzar ciertas "dosis" de consenso, de modo general puede decirse que la Economía Social suele ser definida por su carácter "otrista", alternativo, instituyente. A veces se la sitúa en las antípodas del capital, en tanto propuesta que adquiere de la oposición su eficacia de impugnación. Otras, su apelación vis-à-vis delinea un perfil que comparece ante el "sector público" y el "sector privado" como apuesta de resistencia distanciada de la política y la economía en sentido tradicional.

Dado que no es el objeto de este trabajo profundizar sobre tales acepciones nos limitaremos a hacer dos cortas observaciones. Por un lado, parece una evidencia señalar que estas perspectivas apuestan a ver en la Economía Social una unidad sin fisuras, cuya especificidad supone tipificar un conjunto de características que, en definitiva, sustancializan la definición. El corolario de trascender a los sujetos que hacen otra economía supone separarlos de sus experiencias concretas de trabajo, lo se asemeja bastante a otra forma de alienación. Pero también es posible advertir estos significados actualizados en/por el sentido común, marco lógico en sí mismo de la no conciencia y la reificación. La Economía Social, de tal forma concebida por sus actores, puede presentarse como categoría privativa del deber ser; y sus características, reconvertidas en atributos de distinción.

En contradicción al enfoque de ambas posturas, parece importante señalar que, por otra parte, pueden advertirse como relaciones aquellas dimensiones que se proponen como pares (estáticos e independientes) de opuestos: publico/privado, estado/mercado, política/economía. Franquear el determinismo dualista implica desconocer algunas fronteras y, en cambio, reconocer arenas de lucha por la construcción de sentidos y prácticas. En tal medida consideramos que las relaciones entre lo público y privado, el estado y el mercado, la política y la economía configuran una malla significante que atraviesa a la Economía Social como "sistema histórico de instituciones, valores y prácticas" (Coraggio, 2016:18).

Siguiendo a Coraggio, la economía "no es naturalmente una esfera separada y guiada por sus propias reglas ineluctables, sino objeto de una construcción consciente por actores poderosos que inciden sobre la materialidad de las relaciones sociales y sobre el imaginario social" (2009:29). Por lo cual, de acuerdo con el autor, no sólo se hace posible (pensar) la construcción de una economía otra, sino que los cimientos de ésta no pueden sino ser profundamente políticos respecto a la lógica hegemónica del capital.

$\mathrm{Si}$ bien las definiciones pueden escurrirse por los "contornos" del espectro empírico, no es posible pensar la Economía Social sin considerar que el poder sea una dimensión analizadora, de carácter transversal, vertebradora de cualquier terminología en la medida en que obliga a enfocar las relaciones de fuerza que hacen a la diversidad de sus formas de experiencia. Así, optamos por considerar que la Economía Social no es esfera ni sector sino, ante todo, posición 
en un tablero de fuerzas históricamente asimétricas que tiene al capitalismo como "vórtice de un torbellino de transformaciones en todas las esferas de la vida" (Coraggio, 2007:63).

La Economía Social es, para nosotros, el conjunto de las posiciones que asumen una multiplicidad de actores (con prácticas muy heterogéneas) en torno a la forma de organización productiva que pretenden, para la sociedad que quieren construir. Cabe señalar que con este ensayo de "definición", por demás insuficiente, lo que buscamos es abrir las posibilidades de pensar aquellas "experiencias otras" que escapan a las nociones más tradicionales de la "economía otra". En tal sentido, cualquier concepto será punta de iceberg respecto al conjunto de las experiencias que tienen como proyecto común subvertir la reproducción material y social del capitalismo, en contradicción con y desde su interior (Coraggio, 2009).

Apunta Coraggio que:

Una contraposición efectiva al motor histórico de la acumulación de capital requiere algo más que resistencia (...) es necesario que surja otro sentido alternativo para la sociedad humana, con una fuerza comparable y capaz de encarnarse de manera masiva en imaginarios y estructuras económicas (1998:63).

Como sabemos, las prácticas de construcción de alternativas basadas en la mera resistencia si bien son válidas, usualmente se prueban insuficientes, por su tendencia paliativa, enfocada a atender lo emergente. Más aun, el correlato de aplicarle una lógica coyuntural a problemáticas que son estructurales ha sido, en muchos casos, el "autismo" y la fragmentación respecto a cualquier forma de conciencia colectiva. La problemática de base quizás radica en que el capitalismo debe su legitimidad a la conjunción de la teoría liberal y el sentido común (Cattani, 2004). Este horizonte de naturalización requiere, por lo tanto, la formación de una alternativa socioeconómica, con conciencia política, entendiendo a la última como conciencia de condición y toma de posición (1).

Frente al espectro heterogéneo de actores y prácticas que podrían caber en la categoría, entonces, consideramos necesario avanzar en dirección a un concepto de "economía otra" capaz de priorizar dos aspectos complementarios: su fundamento político y su pluralidad. El primero, en la medida que se busca enfatizar los valores que disputan hegemonía al principio de mercado y racionalidad instrumental propios del sistema capitalista. De forma somera, nos referimos a la autonomía, reciprocidad, equidad y cooperación como condiciones de configuración de una economía alternativa y sustentable en relación a relaciones de la subordinación, competencia, acumulación de capital e individualismo. El segundo, con objeto 
de atender a la multiplicidad de formas de "habitar" otra economía, desde el juego de las posiciones y posibilidades que ofrece cada campo de producción (Bourdieu, 1994).

Apuntamos con esta distinción a enfocar una potencia de transformación, necesariamente emergente del antagonismo y las contradicciones del sistema total que, sin embargo, pareciera soslayada en el sentido común por la inercia del capitalismo, en tanto instituido:

La negación de la dimensión instituyente de la sociedad, el encubrimiento del imaginario instituyente e instituido, va de la mano de la creación de individuos convencionales, cuyos pensamientos y vidas están dominados por la repetición (cualquier otra cosa que hagan es de seguro bien poco) (...)" (Castoriadis, 1997).

Desde allí la Economía Social es capaz de constituirse en "contraposición efectiva" a la acumulación del capitalismo porque las muy diversas manifestaciones que la componen y/o pueden hacerlo emergen de un "lugar" común, imbricado en la misma socialidad: la praxis como proyecto de autonomía (Castoriadis, 1997). De tal modo es razonable que un sentido amplio de la Economía Social no pueda ser contenido por ninguna categoría, pues se conforma parte de las capacidades de transformación de la sociedad instituida.

Hablar de Economía Social es, entonces, también hablar de modos de producir indisciplina. En tal medida refiere a "haceres" (y saberes) muy diversos, contradictorios, de fabricar otra economía y otra sociedad. Y es tal pluralidad de posibilidad de creación y alteración la que nos acerca a pensar más la ES como proyecto que como concepto: he allí su fuerza, pues su potencia nunca acabada ni cesante estalla las clasificaciones funcionales al pensamiento heterónomo.

\section{Hacer universidad/hacer otra economía}

Durante los últimos años en el ámbito universitario se han venido multiplicando las experiencias de trabajo que apuestan a construir una economía e idea de sociedad alternativa a la que propone el sistema capitalista. El entrecruce de actividades concretas en materia de investigación, extensión y docencia se han traducido en proyectos, programas y diversas modalidades de formación que articulan objetivos y líneas estratégicas de acción. Todo ello apunta a mostrar la creciente institucionalización de la Economía Social, como área de trabajo de y en la universidad. 
Cuando nos preguntábamos por el modo de definir a la Economía Social, apelábamos, directamente o indirectamente, a un conjunto de referencias cuyo marco de producción, o articulación teórico-práctica, suele ser bisagra de los vínculos que asume la universidad en torno a la Economía Social (2). De hecho, el marco de apoyatura más concreto de la presente reflexión son las actividades de las que hemos formado parte en el Programa de Economía Social y Solidaria. Las experiencias encuadradas en ese programa, que lleva dos años de trabajo sostenido, generan la continua necesidad de realizar una revisión, en clave crítica, de las propias visiones y acciones.

Hay que decir que, además de la institucionalización, el trabajo que vincula a la universidad con la Economía Social viene asumiendo, de forma más o menos precisa, otra característica relativamente reciente: la externalización. Lo señalado tiene una traducción concreta: los actores individuales o colectivos que en el marco de la universidad realizan actividades relacionadas a la Economía Social, sean de investigación/extensión/docencia, no forman parte del espectro que designa la categoría en el plano teórico y tampoco en el que responde al sentido común. Dado que característica se configura en la dimensión relacional ha de entenderse en el marco de las interacciones que procuran las posibilidades de ver y definir al otro desde una "ubicación" externa, de ajenidad, con lo cual se dificulta transitar acciones que se apoyen en un potencial "nosotros".

De tal manera la universidad aparece en algunos casos llamada, o bien se convoca, a trabajar en conjunto con los actores de la Economía Social. Esta distinción de prácticas y valores que se asumen "propios" de cada ámbito de trabajo, en realidad adquiere mayor sentido en la actualización de ciertos significados en tensión.

Por un lado, emerge de modo persistente la oposición entre lo público y lo privado organizando el sistema de representaciones que definen a los trabajadores de la universidad (3) como trabajadores del estado "al servicio de-", sin formar parte de otra cosa que no que pertenezca a la "órbita" estatal y sus "funciones" y "tareas". La presentificación de este binomio como tal pone en escena uno de los sentidos apuntados inicialmente para definir y ubicar a la ES entre dos "polos" o "extremos", como si en la realidad se constituyeran en "esferas" autónomas, con criterios de caracterización absolutos y distinguibles.

Es particularmente útil recuperar aquí la división conceptual que propone Coraggio (1998), pues resulta superadora del enfoque dicotómico. Según el autor, en su concreción real, las economías responden a lógicas muy distintas, por lo tanto, "sus recursos, actividades y relaciones pueden ser analizados como agregados en tres sectores: un sector de economía empresarial capitalista, un sector de economía pública y un sector de economía popular" (Coraggio, 2009:31). De acuerdo con tal distinción, podríamos considerar la cercanía que tiene 
la universidad respecto al subsistema que responde a la economía pública, cuyo modelo de gestión oscila entre el modelo empresarial y el político-burocrático. No obstante, ninguna de estas lógicas tiende al equilibrio e integración homogénea -más que como matriz ideológica (Gravano, 2013)-. Por lo contrario, se configuran continuamente a partir del conflicto.

Desde y en la cotidianeidad del quehacer universitario, puede advertirse la convivencia, difícilmente armónica, de distintos modos de "hacer universidad". Uno de ellos se apoya en la racionalidad mercantil de la producción de conocimiento que viene instalándose desde los años 80', e implica la privatización de la propia universidad como bien público y "explica" la necesidad de establecer vínculos con el capital (o sector de economía empresarial capitalista), en perjuicio del compromiso social y político de la institución y sus actores (4). Ciertamente la hegemonía de este modelo soporta diferentes matices que, en su mayoría, se prestan al academicismo autocentrado en su propia reproducción.

Pero también hay otros modos de hacer universidad desde los que se entiende al mundo como un conjunto de problemas prácticos que requieren soluciones, antes que como un espectáculo a ser interpretado (Bourdieu y Wacquant, 1995). Desde allí, el trabajo que hace la universidad y sus trabajadores se concibe una construcción colectiva, tendiente a la colaboración y pluralidad. No podemos dudar que este sea un modo alternativo de distribuir aquello que la universidad produce, en el que el trabajo no se encuentra al servicio del capital. Y la condición de posibilidad de ese trabajo apela necesariamente a sostener(se) (en) los valores de solidaridad, reciprocidad, autonomía y cooperación que constituye a los trabajadores de otra economía.

Si es posible considerar la articulación de los tres subsistemas y advertir sus relaciones de complementariedad, sobre cuanto refiere a las superposiciones con el sector de economía empresarial capitalista ¿podríamos pensar los cruces o articulaciones de la Economía Pública con la Economía Popular? ¿No es, acaso, utopía del proyecto en marcha la universidad popular? Con grandes obstáculos y avanzando a pequeños pasos, es posible visibilizar un modo de hacer otra universidad que responde a una idea de indisciplina con la economía dominante, con el acartonamiento de los campos disciplinares, con los modos de concebir y construir el saber, con la perspectiva de extensión y formación docente, entre otras.

La paulatina institucionalización de la Economía Social en la universidad viene a visibilizar una de las formas en las que se contradice el modelo hegemónico de hacer universidad, pero también de hacer Economía Social. A este fin resulta necesario ampliar el sentido de la última, salir de cierta concepción subsidiaria de lo marginal para visualizar el abanico de los trabajadores que se encuentran a diario, ante grandes y pequeños desafíos, haciendo otra sociedad. 
Asimismo, ha de entenderse que la lógica de exterioridad se entrama con las tensiones que emergen de la relación universidad-territorio. Sin entrar en las discusiones y diferentes precisiones que requeriría apelar al concepto de territorio, diremos que, en tanto "construcción social" que configura "una sociedad "localizada" en el espacio" (Roffman, 2005:16), no es posible pensar al territorio sin concebir a la universidad como parte de él.

Desde una concepción que entiende al territorio como una producción inscripta en el campo de poder (Raffestin, 1993), se implica e incluye la totalidad de las relaciones sociales como relaciones de fuerza constitutivas. Ahora bien, desde hace un tiempo en el ámbito universitario se han desarrollado algunas líneas de trabajo que procuran poner en dialogo a la universidad con el territorio, en líneas generales, buscando desarticular el núcleo orgánico-academicista que ha caracterizado una (gran) parte del accionar. Los aportes de ese campo de experiencias han sido ricos y profusos, aunque es de carácter relativamente reciente la discusión que atañe a la problematización del eje que articula las acciones de trabajo. Así, pues, la idea de "poner en dialogo" supone una lectura subyacente que se puede rastrear hacia distintas tradiciones de abordaje, pero en cuya base común se entiende al territorio sustrato material externo a las relaciones sociales (Altschuler, 2013). Es precisamente en el marco de esas relaciones de fuerza, que aparece la necesidad de establecer vínculos, borrando el trazo político del conflicto que es su condición de posibilidad.

La separación que se asoma en el enunciado "universidad y el territorio", es una red significante que sustenta y sostiene la disociación del trabajo que hace la universidad en relación a la Economía Social y los actores que tradicionalmente componen a la última. Ello no hace referencia sino a la territorialidad, asociada con la apropiación y conformación de límites "espaciales", en que concurre la externalidad. Saltar las trincheras de la territorialidad no nos demanda resignar la especifico de cada aportes, sino (usando la noción estrictamente a modo de metáfora) "regionalizar" las posibilidades y capacidades que ofrece la pluralidad.

\section{Nos-Otros}

El primer interrogante refiere al rol de productor de la ES y su relación con la Universidad o más precisamente con el conjunto de actores de la misma que desde un conjunto diverso de programas participan del sector. Retomando críticamente el análisis de Fredrik Barth respecto a los grupos étnicos (1976) y, especialmente, los conceptos de adscripción y auto adscripción, nos proponemos, analizar el proceso de construcción de la identidad del productor. Primero, 
considerando que, como todo proceso de tal característica, genera a la par un conjunto de límites para con otros, como señala el antropólogo noruego:

(...) los grupos étnicos son categorías de adscripción e identificación que son utilizadas por los actores mismos y tienen, por tanto, la característica de organizar interacción entre los individuos (Barth, 1976:10-11).

Dos de las características más relevantes del proceso de constitución identitaria son: la creación de límites del grupo étnico y la persistencia de los mismos. En relación con la ES podemos aplicar este esquema a la formación de un grupo de productores que se definen a sí mismos por su producción artesanal. En tanto artesanos, le asignan a su producción un conjunto de características que parecieran extrapolarse a al total del sector de productores de la ES que le corresponde aquella categoría de adscripción: la no reventa y la unicidad de cada producto "medida" y mediada por el grado de intervención de los saberes del productor. Necesariamente a la lógica de toda grupalidad, tales propiedades sirven a la función de "separar la paja del trigo", es decir, para construirse en relación de diferenciación con otros grupos. La "singularidad" de la producción artesana que "demarca" (relativamente) los límites del grupo, se significa en un proceso que exige la autoadscripción como la adscripción de los otros semejantes, en tanto que "miembros que se identifican a sí mismos y son identificados por otros y que constituyen una categoría distinguible de otras categorías del mismo orden".

A fines de analizar la perspectiva emic podemos distinguir dos grandes "esferas" de interacción: la Universidad y el conjunto de actores que se auto identifican como miembros del sector artesano de la ES. Como ya lo hemos abordado, una mirada analítica no puede admitir que incluso ante la apariencia de "esferas", estas fueran, de modo alguno, homogéneas. No obstante, volviendo a la perspectiva de los actores, es posible advertir allí el efecto homeostasis, respecto a la pluralidad de las prácticas que pueden encontrarse en la universidad.

Advertíamos antes que en la universidad se reconoce cierta visión dominante, cuya propuesta de construcción del conocimiento se concibe al margen de los problemas de los sujetos y el entramado social, vivido como objeto de estudio. Sin dudas respecto a la pervivencia de la ciencia de gabinete(5), no podemos obviar hablar de una visión contra-hegemónica, que plantea la necesidad de llegar a una producción de conocimiento que se elabore de manera colectiva, teniendo presente desde luego, la especificidad propia del aporte académico en términos metodológicos y teórico-conceptuales. 
En pos de superar las perspectivas homogeneizadoras, el esquema analítico de la adscripción relacional se aplica, según hemos señalado, a los productores artesanos. Es posible advertir la existencia de una visión hegemónica del trabajo de producción, que responde a la lógica de elevar el trabajo manual y artesanal a condición sine qua non de pertenencia al sector de la ES. Esta construcción indentitaria sirve no sólo para excluir a otros artesanos en función de su "nivel"/"calidad" de intervención sobre el producto sino también para definir lo que es un producto de ES y quienes son (y no son) los trabajadores de la misma. Estos límites, que oscilan en la transparencia/opacidad de las tramas de poder que los significan, operacionalizan una racionalidad de fiscalización sobre los "productos", incluyendo y excluyendo a la producción intelectual en su sentido amplio y restringido.

Desde tal punto de vista la producción, es aquella que grosso modo se define como el proceso por el cual a través del trabajo un objeto se transforma en un bien determinado para ser comercializado. Tal definición encuentra su partida en la perspectiva académico-hegemónica a partir de la cual la producción opera un mero análisis interpretativo de la realidad, a través de un andamiaje teórico-metodológico, que luego se capitaliza. La contradicción es que si superficialmente ambas posiciones se excluyen mutuamente a partir de los significados asociados al término producción, también se complementan en la misma exclusión, con lo cual se igualan en el plano utilitarista que responde al capital.

Por otra parte, y en coincidencia aquella "otra forma" de hacer universidad, existe una visión que podría decirse contra hegemónica de "hacer economía social" desde los actores que tradicionalmente se inscriben en ella. Nos referimos a un "sector" que mantiene cierta interacción con el sector académico de la ES a fines de generar verdaderas instancias de producción y participación colectiva. Estas dos formas de actores de la economía social coinciden en vislumbrar como necesaria la interacción para construir horizontes de trabajo conjunto, atendiendo a la reciprocidad y solidaridad. Ambos se consideran parte de una construcción mayor sin encumbrar la propia producción como característica univoca del sector de la ES. Desde tal posición nos encontramos con una concepción de la producción en términos amplios, donde la misma mantiene su especificidad tanto como reconoce la necesidad de generar instancias de intercambio y construcción colectiva de conocimiento y de experiencias.

En pos de síntesis, no sobra aquí formular la pregunta que interpela el lugar de la producción académica en este entramado de prácticas y discursos en tensión. A priori, el carácter "material" construido y esgrimido por quienes se autodenominan "productores de la ES", que aquí ubicamos en el espacio hegemónico, obturaría la producción del campo académico. De manera tal que una investigación que asuma la forma de ponencia, artículo, libro o el presente 
análisis emergente de la reflexión sobre nuestras prácticas, quedarían fuera de los límites construidos en y por la grupalidad; límites que, como bien señala Barth, organizan la interacción entre los individuos. Se hace menester problematizar el lugar de los actores del campo académico en este escenario, en tanto los límites no preceden a los grupos sino que surgen de la interacción entre los grupos que se constituyen en relación diferencial. Por lo tanto, es necesario analizar aquellas relaciones a fines de identificar la brecha generada en torno a los saberes, sentidos y prácticas que se tematizan a partir de la tensiones.

\section{La ESS y la ciudad}

La ciudad donde se han llevado (y se siguen llevando) a cabo las diferentes actividades que generaron nuestro análisis es la localidad de Olavarría, ubicada en el centro de la Provincia de Buenos Aires. Fundada en 1867, se encuentra en el centro de la mencionada provincia y es la ciudad cabecera del partido homónimo. De perfil agrícola e industrial (cuya actividad por antonomasia es la industria de extracción pétrea) cuenta con una población de 86.721 habitantes según el último censo realizado en 2010 por el Instituto Nacional de Estadística y Censos (INDEC). El partido de Olavarría, fundado en 1878, engloba, además de la ciudad cabecera, las localidades y parajes de Sierras Bayas, Loma Negra, Sierra Chica, Hinojo, Colonia Hinojo, Recalde, Blanca Grande, Colonia San Miguel, Espigas, Colonia Nievas, Santa Luisa y, Villa La Serranía totalizando 111.708 habitantes (INDEC, 2010).

En relación a la ciudad, otro abanico de posibilidades en aras de problematizar los sentidos locales de la ESS es su lugar en la producción y reproducción de la vida urbana. Cabe aclarar que por "ciudad" nos referimos a la misma en su sentido industrial-capitalista, es decir, a un conjunto de infraestructura de servicios y a una reproducción simbólica que halla su basamento en la apropiación desigual del excedente (urbano en el caso de la ciudad(6)). Si entendemos que la ESS, como modelo de producción político-económica, se halla en las antípodas del capitalismo, su modelo de ciudad habría de recorrer igual latitudes. Si por el contrario aplicásemos el modelo de subsunción de todas las economías a la economía capitalista entonces cabría pensar cuál es el lugar que la ESS ocupa en la construcción de la ciudad. Partimos de la base de considerar que no es una respuesta o la otra, sino que el papel de la ESS en la producción de la vida urbana puede ser analizado poniendo en relación dialéctica ambas propuestas.

La ciudad es mixtura. En ella conviven casi cualquier par de opuestos que pudiéramos construir y en ella se reproducen y, a la vez, reproducen su propia contradicción. Es por esto que el lugar 
de la ESS dentro de la contradicción entre quienes producen la ciudad y quienes la consumen posee un potencial superador en tanto la producción y el consumo responsables pueden obrar como disparadores de un ejercicio reflexivo que apunte a construir un modelo de ciudad más igualitario.

Un segundo nivel de potencialidad se halla en que, como mencionamos con anterioridad, hablar de ESS es hablar de indisciplina y de heterogeneidad y estos son valiosos aspectos a la hora de pensar un proyecto de ciudad. Para que este potencial reformador se ponga en marcha es necesario que la ESS como posición reconozca a la ciudad como destinatario de su accionar.

\section{Desplegar}

El fragmento es pliegue. Si se lo despliega, explica. Si se lo deja en su envoltorio vela sus implicancias. (...) Develar el fragmento afecta la perspectiva, descubre latencias y posibles. El fragmento es un todo concreto cuyos filamentos rozan a las otras situaciones.

Vecinocracia. $(\mathrm{Re})$ tomando la ciudad.

El objetivo de sistematizar las visiones, definiciones, perspectivas $y / 0$ enfoques que se activan y revisan desde las experiencias de trabajo no pretende borrar las huellas del aporte diferencial de cada uno de los actores que componen a la Economía Social. Apelamos a concebir instancias conjuntas de reflexión y participación que apunten a la transversalidad como condición que, a nuestro juicio, debe caracterizar a la producción colectiva desde la convergencia de saberes.

A lo que apuntamos es a plantear instancias cuyo horizonte de integralidad se construya a partir de la solidaridad dentro del proceso que conjuga distintos modos de hacer una Economía Social Solidaria y Popular. En pos de ello la solidaridad no puede ser puntada final sino aspecto co-constitutivo de la otra economía en su sentido más amplio, incluyente, democratizador. En tal sentido, creemos que la solidaridad, usualmente asociada a la emergencia-crisis-necesidad, debe recuperar su sentido etimológico que, del latín solidus, refiere a lo compacto, lo sólido, lo unido. En definitiva la pertenencia a una comunidad. Con tal propuesta el acento se baja de la homogeneidad, para ponerse en la aguja con la que cada actor da sus puntadas. 
El fundamento de esta mirada descansa, precisamente, en la potencialidad de incluir aquellas formas "otras" de hacer una "economía otra". Entre ellas, la universidad -o bien, parte de ella, si queremos ser ecuánimes- es solo un pliegue de la trama posible. De la misma manera lo son los productores artesanos. $Y$ las cooperativas, el taller pequeño, los espacios culturales independientes, las organizaciones autogestivas. La lista no puede sino resultar tan extensa como incompleta. Pero nos descubre entramados y, por ello, desafiados a trabajar juntos.

\section{Notas}

(1) No aludimos aquí al posicionamiento singular que el individuo asume en tanto individuo. Si bien sus acciones son, en algún punto, determinantes del cambio, la conciencia. de condición sólo puede concretarse encuadrada en su dimensión constitutiva, que es histórico-social y, por lo tanto, es eminentemente colectiva.

(2) Cabe señalar, por el carácter generalista de la aseveración, que estos modos de vinculación son muy distintos entre sí, incluso antagónicos, porque se configuran a partir de las discusiones y prácticas que tensionan las formas de concebir la relación entre el territorio y la universidad.

(3) Seguimos aquí el concepto de trabajo que propone Marx. Entendiéndolo como la actividad transformadora que media entre el hombre y la naturaleza, es en sí mismo acto social de contradicción con lo dado. En este sentido, cuando referimos a los trabajadores de la universidad queremos significar al trabajo como actividad productiva en sentido amplio, sin distinguir entre las actividades consideradas económicas y las que no.

(4) "Las políticas del Banco Mundial (...) proponen organizar el trabajo académico basándose en la evaluación por "eficiencia" (con indicadores cuantitativos) y promover una investigación cada vez más dependiente de agencias, con objetivos prioritarios que fragmentan los espacios universitarios y los vinculan a las grandes corporaciones (...) En este proceso identifico dos fases. En la primera, que va del inicio de la década de 1980 hasta mediados de la década de 1990, se expande y se consolida el mercado nacional universitario. En la segunda, al lado del mercado nacional, emerge con gran fuerza el mercado transnacional de la educación superior y universitaria, el que a partir del final de la década es transformado en solución global de los problemas de la educación por parte del Banco Mundial y de la Organización Mundial del Comercio" (Souza Santos, 2006: 27)

(5) La referencia es una metáfora que alude a la designación que se le ha dado en el campo de la antropología a los etnólogos clásicos.

(6) Dicha totalidad está formada por el campo y la ciudad pensados como una unidad de opuestos

\section{Bibliografía}

Altschuler, B. (2013) Territorio y desarrollo: aportes de la geografía y otras disciplinas para repensarlos.

Barth, F. (comp.) (1976). Los grupos étnicos y sus fronteras. La organización social de las diferencias culturales. Introducción. FEC, México D.F. pp. 9-49. 
Bourdieu, P. (1994) El campo científico. Redes: revista de estudios sociales de la ciencia. 1(2), 129-160. Disponible en RIDAA Repositorio Institucional de Acceso Abierto. http://ridaa.unq.edu.ar/handle/20.500.11807/317

Bourdieu, P., Wacquant, L. (1995). Por una antropología reflexiva. México: Grijalbo.

Castoriadis, C. (1997) Poder, política, autonomía. Un mundo fragmentado. Buenos Aires, Altamira.

Cattani, D. (comp.) (2004). La otra economía. Contenidos esenciales. Buenos Aires, Altamira.

Coraggio, J. L. (1998) Economía urbana. La perspectiva popular. Abya-Yala, Quito.

Coraggio, J. L. (2007). Una perspectiva alternativa para la economía social: de la economía popular a la economía del trabajo. La Economía Social desde la periferia. Contribuciones latinoamericanas, Altamira, Buenos Aires.

Coraggio, J. L. (2009). Los caminos de la economía social y solidaria. Presentación del dossier. Íconos, 2009, no 33, p. 29-39.

Coraggio, J. L. (2016) La economía social y solidaria (ESS): niveles y alcances de acción de sus actores. El papel de las universidades. Economía Social y Solidaria: conceptos, prácticas y políticas públicas (Puig coord.) Hegoa, Bilbao.

De Sousa Santos, B. (2005). La Universidad en el siglo XXI: para una reforma democrática y emancipadora de la universidad. Centro de Investigaciones Interdisciplinarias en Ciencias y Humanidades, UNAM; México.

Gravano, A. (2013). Homeostasis múltiple del sistema urbano, la gestión de servicios públicos y los imaginarios identitarios de ciudades medias: marcos y proyecciones. IV Jornadas de Antropología Social del Centro. Olavarría, 2, 3 y 4 de Octubre de 2013.

Raffestin, C. (1993) Por uma geografia do poder. São Paulo, Ática.

Roffman, A. (2005) Universidad y desarrollo local. Prometeo, Buenos Aires. 